\title{
MAKE A MOVE : ENHANCING FALLS PREVENTION THROUGH WORKING IN PARTNERSHIP
}

\section{Christine Pollachini and David Riches \\ Western Sydney Area Health Service}

It has often been said that working in partnerships is 'like dancing with an octopus'. However, a coalition of six area health services and the NSW Department of Health's Injury Prevention and Policy Unit working on a falls prevention program for people aged 65 years and over, may disagree. The six area health services are: Western Sydney, South Western Sydney, South Eastern Sydney, Northern Sydney, Central Sydney, and Central Coast Health. This article outlines the process of working in partnership to prevent falls in older people and describes the advantages to collaboration in the development of planning frameworks across area health services and the NSW Department of Health.

Initially, the directors of health promotion in these six area health services met to discuss how they could work together to increase resources for a major health issue. Falls in older people was identified as the issue to focus on, NSW Health became interested in the collaboration, and the Make a Move program was born.

The Make a Move program has five objectives, which are to:

- increase preventive awareness of risk factors, and in particular the benefits of gentle exercise to reduce the risk of falling among the older community (65 years and over) across Sydney;

- increase awareness among carers and supporting relatives of the increased risk of falls in older people;

- develop suitable communication strategies for older people in key communities from a non-English speaking background;

- substantially increase local programs providing gentle exercise programs for older people;

- develop a suitable evaluation methodology within the key target group to measure increased participation in gentle exercise programs.

The Injury Prevention and Policy Unit offered project funding in the first year, and in August 2000 an executive officer, managed by the Western Sydney Area Health Service, was employed. The first year was directed at raising awareness of the risk factors of a fall and the benefits of physical activity. Focus testing identified
'Make a Move-It's Never Too Late' as an appropriate message to promote the issue of falls prevention.

A Make a Move management committee was established, with representation from across the six area health services; and there were three sub-committees, one each for communication, injury, and evaluation. Evaluation of the overall project was put into place, including monitoring of the management committee. The Capacity Building Checklist 1 'Assessing the Strength of a Coalition' was used to review the committee. ${ }^{1}$

At the initial stage, members of the committee and subcommittees had unclear expectations, both of the project and their roles. Consequently, all committee and subcommittee minutes were circulated to members via a listserve to create a common understanding of the process.

Identified strengths of the partnership model are: teamwork and alliances, combined knowledge and expertise, and confirmed and accepted leadership.

Working across area health services can be a challenge. However, this program has shown that with increased resourcing, and commitment to a priority issue, it is worth pursuing. An external consultant is conducting a comprehensive evaluation to determine the benefits of future collaborations of this type.

\section{ACKNOWLEDGMENTS}

The Make a Move management committee; the Make a Move communication, injury, and evaluation and subcommittees; and representatives of the area health services and the NSW Department of Health's Injury Prevention Policy Unit.

For more information about the resources developed for Make a Move visit www.health.nsw.gov.au/public-health/healthpromotion/improve/injuryprev/fallsprevention/ falls_tips.htm or www.nsh.nsw.gov.au/Healthlnfo/ HealthProm/ProgProj/MakeMove/Index.htm.

\section{REFERENCE}

1. Public Health Division. Indicators to Health with Capacity Building in Health Promotion. Sydney, NSW Department of Health, 2000. www.health.nsw.gov.au. 